\title{
Determination and comparison of sludge reduction rates caused by microfaunas' predation
}

\author{
Peng Liang ${ }^{\mathrm{a}}$, Xia Huang ${ }^{\mathrm{a}, *}$, Yi Qian ${ }^{\mathrm{a}}$, Yuansong Wei ${ }^{\mathrm{b}}$, Guoji Ding ${ }^{\mathrm{c}}$ \\ a Environment Simulation and Pollution Control State Key Laboratory, Department of Environmental Science and Engineering, \\ Tsinghua University, Beijing 100084, PR China \\ ${ }^{\mathrm{b}}$ Department of Water Pollution Control Technology, Research Center for Eco-Environmental Sciences, Chinese Academy of Sciences, \\ P.O. Box 2871, Beijing 100085, PR China \\ ${ }^{\mathrm{c}}$ National Institute for Environmental Health and Related Product Safety, Chinese Center for Disease Control and Prevention, \\ Beijing 100050, PR China
}

Received 24 May 2004; received in revised form 6 April 2005; accepted 6 April 2005

Available online 13 June 2005

\begin{abstract}
Using micorfauna to reduce excess sludge is a potentially effective ecological technology and scaling the rate of sludge reduction rate is the first step. A method to scale the rate of sludge reduction caused by microfauna was proposed, and comparison of sludge reduction rates induced by four microfaunas was carried out. The principle of this method is based on the change of carbon forms. The rate of sludge reduction was correlated with the rate at which solids were changed into liquid and gas. Four microfaunas, including Aeolosoma hemprichi, Daphnia magna, Tubifex tubifex and Physa acuta, were cultured with sterilized sludge in a covered sterilized bottle and were then isolated from the atmosphere above the liquid phase. The rates of sludge reduction using the four microfaunas were $0.8,0.18,0.54$ and $0.1 \mathrm{mg}$-sludge/(mg-Microfauna $\mathrm{d})$, respectively, changing with the microfaunas' phylum or class and body size. Based on the change of carbon (C) forms, the proposed method produced accurate results similar to those produced using the direct measuring method.
\end{abstract}

(C) 2005 Elsevier Ltd. All rights reserved.

Keywords: Municipal wastewater; Sludge reduction; Microfauna; Predation

\section{Introduction}

The conventional activated sludge (CAS) process is the most widely used biological wastewater treatment process for both domestic and industrial wastewaters. One of the drawbacks of the CAS process, however, is its high sludge production. Along with the continuous strengthening of environmental and legislative controls on the excess sludge produced during the biological treatment of wastewater, the costs of excess sludge treatment and disposal have steadily increased. As noted by

\footnotetext{
* Corresponding author. Tel.: +86 10 62772324; fax: +86 10 62771472.

E-mail address: xhuang@tsinghua.edu.cn (X. Huang).
}

Low et al. (2000), Mayhew and Stephenson (1997), Wei et al. (2003a,b), excess sludge treatment and disposal may account for $60 \%$ of the total operating costs in municipal wastewater treatment plants. New technologies for excess sludge reduction are thus an urgent need and have been researched by Chen et al. (2001), Low and Chase (1999), Low et al. (2000), Rocher et al. (1999), Kamiya and Hirotsuji (1998), Saby et al. (2002).

With advantages such as low cost and no secondary pollution, this technology which using microfaunas' predation to reduce excess sludge has recently begun to receive increasing attention by some researchers i.e. Ghyoot and Verstraete (1999), Ratsak et al. (1996), Rensink and Rulkens (1997), Salvado et al. (1995). Wei et al. (2003b) have proven the effectiveness of using 
microfauna to reduce excess sludge, but these results were based only on the relation between the yield of sludge and the density of microfauna, i.e., the sludge yield and the microfauna's density were negatively correlated. As the sludge yield is easily affected by many factors such as environmental factors (temperature, the classes of bacteria) and operational factors (sludge retention time and the ratio of food to microorganism $(\mathrm{F} / \mathrm{M})$ ), these reduction scales obtained by comparing the correlation of sludge yield and the microfauna's density were inaccurate and indirect. However, Luxmy et al. (2001) suggested that metazoa could not reduce sludge production in an aeration tank. Ellissen et al. (2003) believed that microfauna could reduce sludge, but argued about which species of microfauna could reduce sludge best. These contradictory opinions were related to the lack of effective methods of detecting the rate of sludge reduction caused by microfauna. Therefore, it is important to accurately determine the reduction scale or rate since this is helpful to compare and choose types of microfaunas as sludge predators.

The difficulties associated with the direct measurement of sludge reduction rate arise from the problematic direct quantification of the weight of the microfauna and the sludge and from the difficult separation of the microfauna from the sludge. Using isotope as a tracer dose is a common practice in biology, but this method can only measure the microfauna's ingestion rate, which is different from the reduction rate. In addition, the isotope test must be carried out very carefully, and is thus not commonly used in environmental engineering. One of current challenges of sludge reduction induced by predation is to establish a method, which is highly credible and easily operated to quantify sludge reduction rate.

In this research, a new method based on the transformation of the $\mathrm{C}$ element in sludge was proposed to measure the sludge reduction induced by the predation behavior of microfauna. Results of using this method was subsequently compared with those of the direct measurement based on sludge's weight. Four microfaunas and sludge samples from six wastewater treatment plants were thus examined by this method in order to find the relationship between the reduction rates and the sorts of microfaunas or the sludge from different wastewater treatment plants.

\section{Methods}

\subsection{Species of microfaunas}

Four species of metazoa: Aeolosoma hemprichi (Fig. 1a), Daphnia magna (Fig. 1b), Tubifex tubifex (Fig. 1c), and Physa acuta (Fig. 1d) were collected from aeration tanks and used for this study. The taxonomic characteristics of these species are described as follows. A.
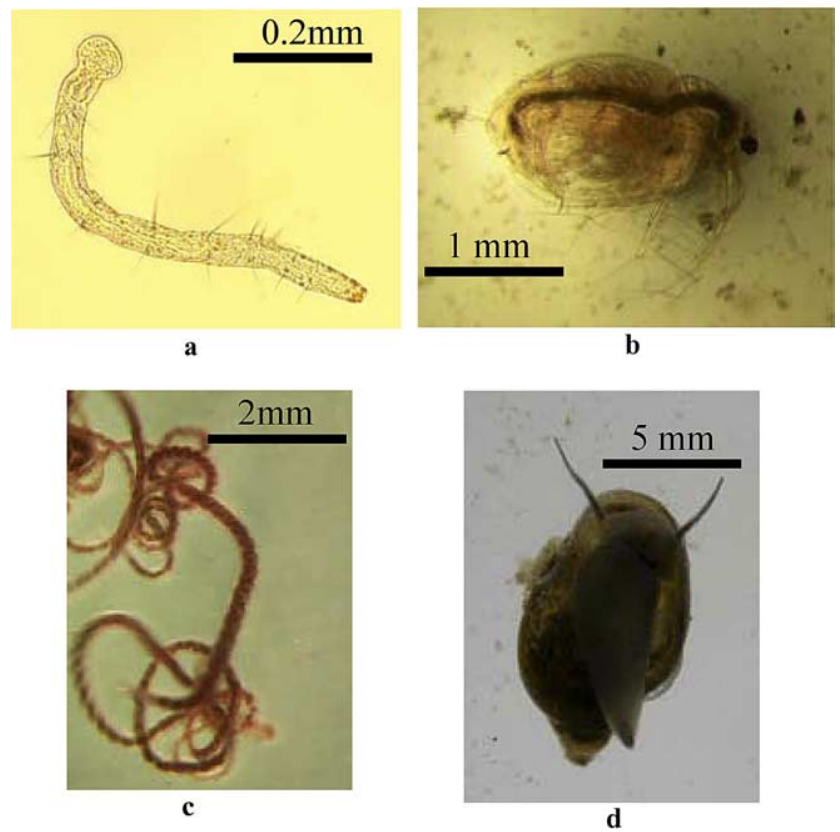

Fig. 1. The pictures of microfaunas: (a) Aeolosoma hemprichi, (b) Daphnia magna, (c) Tubifex tubifex, and (d) Physa acuta.

hemprichi (Annelida: Aeolosomatidae) is a minute meiofaunal Annelida. Its body is about $0.05 \mathrm{~mm}$ in width and $0.8 \mathrm{~mm}$ in length. The epidermal is covered with orangered glands and red oil globules. The prostomium is comparatively large, roundish and somewhat dorsoventrally flattened. Sigmoid setae are absent and the longest hair setae is less than $0.16 \mathrm{~mm}$. D. magna (Arthropoda, Daphnidae) is a crustacean, like a crab or a lobster, and has a hard, outer shell. Its length is approximately $2-5 \mathrm{~mm}$. The first pair of antennae is very short and close to the rostrum. A paired caecum is visible just behind the mouth. A thick spine on the abdomen closes the brood pouch. T. tubifex (Annelida, Tubificidae) is a slender segmented worm that may grow up to $100 \mathrm{~mm}$ in length. It has between 34 and 120 body segments. On each side of its body, there are a bundle of chitinous bristles (setae). The worm is red in color. $P$. acuta (Mollusca, Physidae) is a pulmonate snail. Its shell is elongate-ovate, thin, smooth, moderately lustrous and translucent, and light fawn-colored, and is covered by fine, close-set lines of growth, and non-perceptible spiral lines. Its spire is short, and its suture is slightly impressed. The aperture is large, ear-shaped, and about $3 / 4$ of the total length of the shell. The largest shell is $16 \mathrm{~mm}$ in length and $9 \mathrm{~mm}$ in width.

\subsection{Experimental methods and analysis}

As shown in Fig. 2, microfaunas which were separated from activated sludge taken from a municipal wastewater plant in Beijing were disinfected in sequence by salt $(0.4 \% \mathrm{NaCl}$, to make the microfaunas vomit the 


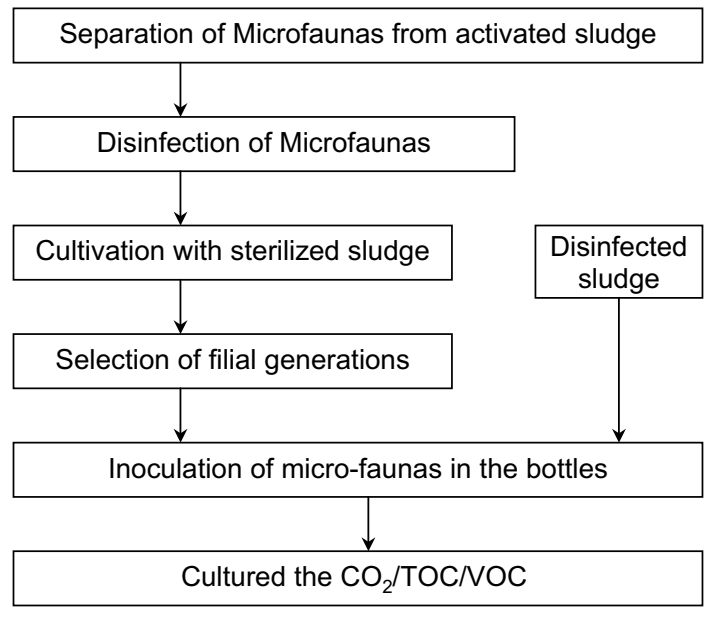

Fig. 2. A flow chart of the experiment in this study.

sludge from their stomachs), chlorine dioxide $(0.0001 \%)$, penicillin and chloramphenicol $(0.01 \%)$, and then cultivated with sterilized sludge (Fan et al., 2001). In the cases of $A$. hemprichi and D. magna, considering that their bodies were small and sensitive to salt and chlorine, penicillin and chloramphenicol $(0.001 \%)$ were only used as disinfectant. The filial generations were selected as the object microfaunas using adjustable pipettes, and were considered as bioclean individuals. The selected microfaunas were placed into glass bottles (see Fig. 3). The volumes of the bottles were different for each microfauna because of their different body sizes. The bottles of $12 \mathrm{ml}$ were used for A. hemprichi and D. magna, and the bottles of $18 \mathrm{ml}$ for T. tubifex and the bottles of $135 \mathrm{ml}$ for $P$. acuta, but all the volume ratio of gas to sludge in bottles were set the same (about 3:1). Both the bottles and the sludge were sterilized at $121{ }^{\circ} \mathrm{C}$ (to prevent the metabolism of activated sludge from affecting the amount of $\mathrm{CO}_{2}$ produced during predation), and different amounts of object microfaunas were then inoculated in the bottles. The bottles were covered and placed in an incubator at $25^{\circ} \mathrm{C}$. Few live anaerobium were in the bottles because of the sterilized sludge, and the amount of gas produced by fermentation could thus be ignored. As $\mathrm{CO}_{2}$ correspondingly increases with decreasing $\mathrm{O}_{2}$, the gas pressure in the bottles stays in balance.

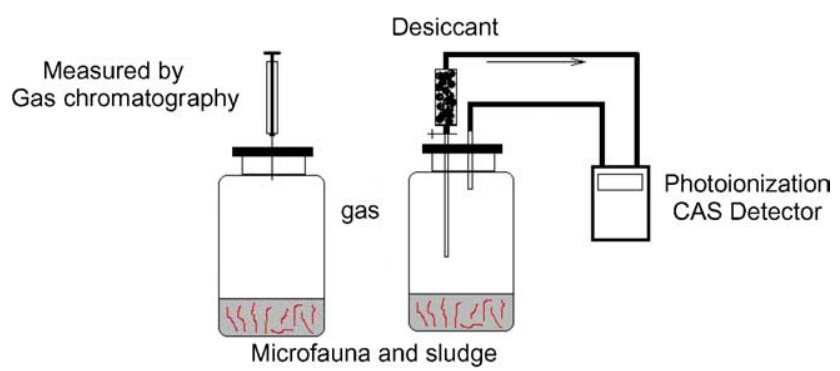

Fig. 3. Diagram of equipment for measurement of $\mathrm{CO}_{2}$ and VOC.
The setup used for this research is shown in Fig. 3. $\mathrm{CO}_{2}$ was measured every 4 or $6 \mathrm{~h}$ by a gas chromatograph (TC-14, Shimadzu, Shuzhou, China), each time with the volume of sampling by a syringe set at $200 \mu \mathrm{l}$ (Fig. 3, left). The dissolved total organic carbon (DOC) was determined by a total organic carbon analyzer (TOC-5000A, Shimadzu, Kyoto, Japan) after the experiment was over. The setup was also used (Fig. 3, right) to compare the amount of volatile organic carbon (VOC) with $\mathrm{CO}_{2}$ in the gas. Unlike the $\mathrm{CO}_{2}$ intermittent determination in the gas, the changes of VOC concentration in the gas were continuously monitored by an online photoionization gas detector (VOC detector, PGM7240, RAE System, Sunnyvale, America). The working volume of the bottles shown on the right side of Fig. 3 was $1 \mathrm{~L}$, which was much larger than the volume of the channels in order to minimize the impact of bottle volume on the channel. Anhydrous sodium sulfate was used as a desiccant in the gas-in channel because VOC determination can be affected by water vapor in gas.

The amounts of sludge used were sufficient for the growth of the microfaunas during the whole experiment period (sludge amounts for $A$. hemprichi and D. magna: 2-4 ml; for T. tubifex and P. acuta: 30-35 ml). Results of our previous research using microfauna such as $A$. hemprichi indicated that the growth rate of the microfauna was not dependent on whether the sludge was sterilized or not, and the microfauna would not consume the viable bacteria in the sludge floc selectively. It is therefore reasonable to infer that the rates of sludge reduction in this study were unchanged whether sludge was sterilized or not.

\subsection{Statistical analysis}

The data were fitted through a linear regression (line of least squares fitting). The related coefficients were the Pearson coefficients $(P)$, which represented the degree of linear correlation. The tests of significance were based on 2-tailed tests. If the 2-tailed test coefficient is lower than 0.05 , the arguments are significantly correlated with the dependent variables, and thus the regression coefficient is significant. The related coefficients $P$ values and the 2-tailed test coefficients were calculated by the software SPSS (Statistical Program for Social Sciences). Using the statistical analyses, $P$ values, correlation level and significant 2 -tailed coefficients were obtained and listed under the figures.

\section{Results and discussion}

\subsection{Principle}

The principle of using microfauna to reduce excess sludge comes from the food chain. Materials and energy 
are dissipated (or lost) when they flow in the food chain, and hence the microfaunas' predation leads to sludge reduction. Reducing sludge is accomplished by changing the sludge from a solid to a liquid or gas. By measuring the rate at which non-solid material increases, the rate of sludge reduction can be determined. The elements of sludge or biomass include elements such as carbon $(\mathrm{C})$, oxygen $(\mathrm{O})$, nitrogen $(\mathrm{N})$, phosphorus $(\mathrm{P})$, and sulfur (S), but $\mathrm{C}$ is generally present in the greatest amounts (50\% or so). Therefore $\mathrm{C}$ was selected as the object element in this study. As shown in Fig. 4, when sludge in solid form is consumed by microfauna, some parts of the sludge are synthesized into microfaunas' bodies, and at the same time other parts of the sludge as well as the microfaunas' bodies in solid form are decomposed by catabolic excretion. The hydrolyzed amount of sludge in solid form can be determined by the blank test. The non-solid $\mathrm{C}$ comprises four parts: inorganic $\mathrm{C}$ in liquid and gas, and organic $\mathrm{C}$ in liquid and gas. The inorganic $\mathrm{C}$ in liquid and gas has its own balance (to be proved in the following results).

\subsection{Calculation of the sludge reduction rate}

Based on the process illustrated in Fig. 4, reduced sludge is changed from solid to liquid or gas. Therefore, the rate of sludge reduction can be therefore calculated by measuring the rate at which non-solid $\mathrm{C}$ increases. As shown in Eq. (1), the production rate of non-solid C equals the sum of the two parts $R_{\mathrm{IC}}$ and $R_{\mathrm{OC}}$ :

$$
\begin{aligned}
R_{\mathrm{S}} & =R_{\mathrm{NS}-\mathrm{C}} / 0.5=\left(R_{\mathrm{IC}}+R_{\mathrm{OC}}\right) / 0.5 \\
& =\left(R_{\mathrm{IC}-\mathrm{G}}+R_{\mathrm{IC}-\mathrm{S}}+R_{\mathrm{OC}-\mathrm{G}}+R_{\mathrm{OC}-\mathrm{s}}\right) / 0.5,
\end{aligned}
$$

where $R_{\mathrm{S}}$ is the rate of sludge reduction, $\mathrm{mg}-\mathrm{C} /(\mathrm{mg}-$ Microfauna dry weight d); $R_{\text {NS-C }}$ is the rate at which non-solid $\mathrm{C}$ increases, $\mathrm{mg}-\mathrm{C} /(\mathrm{mg}$-Microfauna dry weight d); 0.5 is the ratio of $\mathrm{C}$ in the sludge; $R_{\mathrm{IC}}$ is the rate at which inorganic $\mathrm{C}$ increases, including the rates of inorganic $\mathrm{C}$ both in the gas $\left(R_{\mathrm{IC}-\mathrm{G}}\right)$ and in the sludge liquor $\left(R_{\mathrm{IC}-\mathrm{S}}\right)$, mg-C/(mg-Microfauna dry weight $\left.\mathrm{d}\right)$; and $R_{\mathrm{OC}}$ is the rate at which organic $\mathrm{C}$ increases, including the rates of increase of organic $\mathrm{C}$ both in the gas $\left(R_{\mathrm{OC}-\mathrm{G}}\right)$ and in the sludge liquor $\left(R_{\mathrm{OC}-\mathrm{S}}\right), \mathrm{mg}-\mathrm{C} /(\mathrm{mg}-$ Microfauna dry weight d).

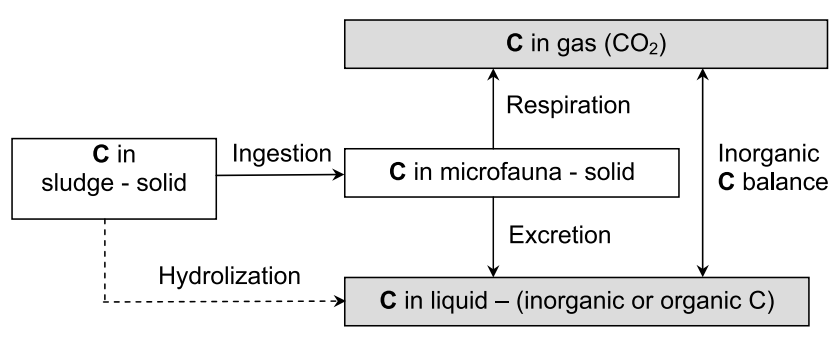

Fig. 4. Transformation of $\mathrm{C}$ element in food chain.

\subsubsection{Calculation of $R_{I C}$}

$R_{\mathrm{IC}}$ is the sum of $R_{\mathrm{IC}-\mathrm{G}}$ and $R_{\mathrm{IC}-\mathrm{S}} \cdot R_{\mathrm{IC}-\mathrm{G}}$ can be directly calculated through the measurement of the amount of $\mathrm{CO}_{2}$ in the gas, since the inorganic $\mathrm{C}$ in the gas was only $\mathrm{CO}_{2}$. As for $R_{\mathrm{IC}-\mathrm{s}}$ it was difficult to measure directly because the inorganic $\mathrm{C}$ in the sludge liquor included $\mathrm{H}_{2} \mathrm{CO}_{3}, \mathrm{HCO}_{3}^{-}$and $\mathrm{CO}_{3}^{2-}$, however, it can be determined from the relationship of the equilibrium of inorganic $\mathrm{C}$ between the gas and the sludge liquor. The equilibrium of $\mathrm{CO}_{2}$ between gas and pure water conforms to Henry's law. In order to know whether the relationship of the inorganic $\mathrm{C}$ in the sludge liquor and in the gas conforms to Henry's Law or not, a preliminary experiment was carried out in this study. At the beginning of the experiment, different volumes of pure $\mathrm{CO}_{2}$ (from 0 to $700 \mu \mathrm{l}$ ) were injected into bottles containing sterilized sludge liquor. This experiment was repeated 3 times, and the same sort and the same volume of sludge were used in the experiments. After $4 \mathrm{~h}$ at $25^{\circ} \mathrm{C}$, the concentration of $\mathrm{CO}_{2}$ in the gas was measured (Fig. 5). The results in Fig. 5 clearly showed that the amount of $\mathrm{CO}_{2}$ absorbed in sludge liquor was more than that absorbed in pure water. The reason is that the sludge liquor acted as a buffer solution to $\mathrm{CO}_{2}$, and thus could absorb some additional $\mathrm{CO}_{2}$. However, when the concentration of $\mathrm{CO}_{2}$ was higher than $5000 \mathrm{ppm}$, the slope of the sludge liquor was the same as that of the pure water, suggesting that the sludge liquor could not absorb additional $\mathrm{CO}_{2}$. Therefore it can be concluded that the relationship between the inorganic $\mathrm{C}$ in the sludge liquor and in the gas conformed to Henry's Law at $\mathrm{CO}_{2}$ concentration, over $5000 \mathrm{ppm}$.

The coefficient of $\mathrm{CO}_{2}$ distribution in the sludge liquor was experimentally calculated as $0.56 \mathrm{mmol}-\mathrm{CO}_{2} /$ mmol-inorganic $\mathrm{C}$, which did not change if both the ratio of gas to the sludge liquor in the bottle and the type of sludge used in the experiment were the same. Therefore, $R_{\mathrm{IC}}$ was determined in this study according to the following equation: $R_{\mathrm{IC}}=R_{\mathrm{IC}-\mathrm{G}} / 0.56$.

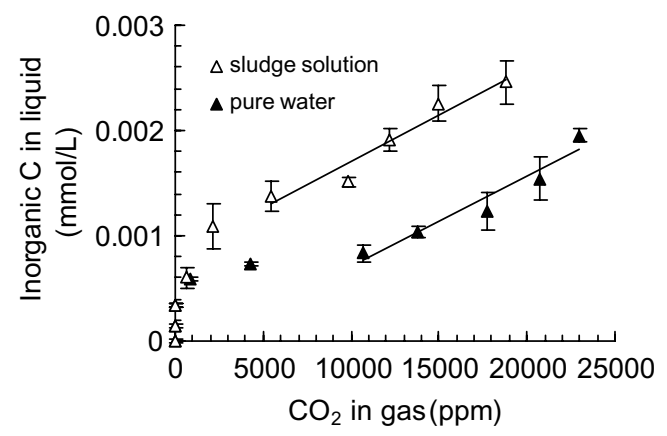

Fig. 5. The relationship of the inorganic $\mathrm{C}$ in sludge liquor and in gas. Concentrations of IC are given as mean $\pm \mathrm{SD}$ of four cores. $P$ of sludge solution is 0.969 , the correlation is significant at 0.01 level, the significant 2-tailed is $0.006 P$ of pure water is 0.97 , the correlation is significant at 0.01 level, the significant 2-tailed is 0.006 . 


\subsubsection{Calculation of $R_{O C}$}

The production rate of organic C $R_{\mathrm{OC}-\mathrm{s}}$ in sludge liquor was calculated by the DOC concentration of the sludge liquor in different bottles. The production rate of organic $\mathrm{C} R_{\mathrm{OC}-\mathrm{G}}$ in the gas can be ignored since the production of VOC was experimentally found to be less than $0.1 \%$ of that of $\mathrm{CO}_{2}$ in the gas, i.e., the concentration of VOC was 400-700 ppb, while the concentration of $\mathrm{CO}_{2}$ was $1000-20,000 \mathrm{ppm}$. Hence, $R_{\mathrm{OC}} \approx R_{\mathrm{OC}-\mathrm{S}}$ and Eq. (1) can be simplified as follows:

$R_{\mathrm{S}}=\left(R_{\mathrm{IC}-\mathrm{G}} / 0.56+R_{\mathrm{OC}-\mathrm{s}}\right) / 0.5$.

\subsection{Rate of sludge reduction caused by \\ T. tubifex predation}

In order to illustrate the process of calculating the sludge reduction rate based on the proposed method, T. tubifex was first taken as a test. Their bodies were large enough to directly determine the sludge reduction rate so that the method based on the change of carbon forms could be compared with the direct measurement method.

\subsubsection{Increasing rate of $\mathrm{CO}_{2}$ caused by}

\section{T. tubifex predation}

Results clearly showed that the concentration of $\mathrm{CO}_{2}$ produced in the predation of $T$. tubifex increased in correspondence with increasing time and number of $T$. tubifex organisms (Fig. 6). The rate of $\mathrm{CO}_{2}$ increase calculated from Fig. 6 was $R_{\mathrm{CO}_{2}}=152.78 \mathrm{ppm} /$ (ind-Tubi$f e x \mathrm{~h})=0.000153 /$ (ind-Tubifex $\mathrm{h})($ Table 1), i.e.,

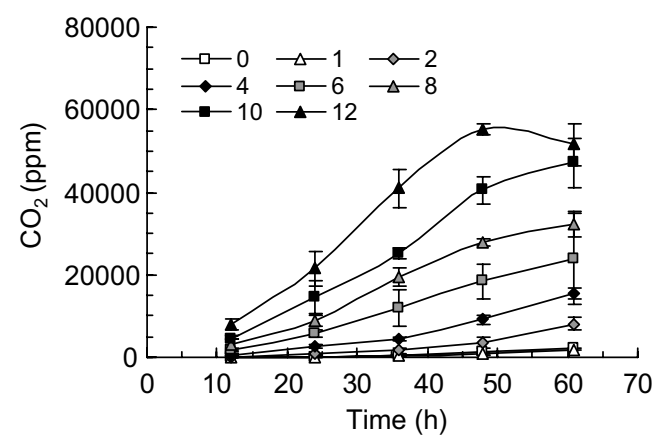

Fig. 6. $\mathrm{CO}_{2}$ increased in the gas at different times with different numbers of T. tubifex organisms. Concentrations of $\mathrm{CO}_{2}$ are given as mean \pm SD of five cores.

$$
\begin{aligned}
R_{\mathrm{IC}-\mathrm{G}} & =\frac{R_{\mathrm{CO}_{2}} \times V \times M_{\mathrm{C}} \times 24}{24.5 \times W}=\frac{R_{\mathrm{CO}_{2}} \times 36 \times 12 \times 24}{24.5 \times 0.5} \\
& =0.129 \mathrm{mg}-\mathrm{C} /(\mathrm{mg}-\text { Tubifex } \mathrm{d}),
\end{aligned}
$$

where the unit of $R_{\mathrm{IC}-\mathrm{G}}$ is $\mathrm{mg}-\mathrm{C} /(\mathrm{mg}-$ Tubifex $\mathrm{d}) ; 24.5$ is the ideal gas constant at $25^{\circ} \mathrm{C} ; V$ is the volume of the bottle, $24 \mathrm{ml} ; M_{\mathrm{C}}$ is the $\mathrm{C}$ atomic mass, $12 ; 24$ is the number of hours per day; and $W$ is the dry weight per individual Tubifex, experimentally measured as $0.5 \mathrm{mg}$ (in order to have a uniform unit to compare, the weight of the microfauna is in milligrams).

The same experiments were repeated four times, and the number of Tubifex inoculated into the bottles was within a range from 0 to 20 individual Tubifex. The calculated $R_{\text {IC-G }}$ values were within a range of 0.13 $0.14 \mathrm{mg}-\mathrm{C} /(\mathrm{mg}-$ Tubifex $\mathrm{d})$, with a standard deviation of $0.0095 \mathrm{mg}-\mathrm{C} /(\mathrm{mg}-$ Tubifex $\mathrm{d})$.

\subsubsection{Rate of organic $C$ increase caused by T. tubifex predation}

After the experiment was over, the sludge liquor was then filtrated through a membrane with a pore size of $0.45 \mu \mathrm{m}$ for DOC determination. The results in Fig. 7 showed that the slope of the line was $0.0157 \mathrm{mg}$-DOC/ (ind-Tubifex d). For easy comparison, the rate of organic C increase was calculated as $R_{\mathrm{OC}}=0.0157 / 0.5=$ $0.0314 \mathrm{mg}$-DOC/(mg-Tubifex $\mathrm{d})$, where 0.5 is each Tubifex's dry weight. Based on Eq. (2), the $R_{\mathrm{S}}$ can be calculated as follows:

$$
\begin{aligned}
R_{\mathrm{S}} & =\left(R_{\mathrm{IC}-\mathrm{G}} / 0.56+R_{\mathrm{OC}-\mathrm{s}}\right) / 0.5=(0.23+0.0314) / 0.5 \\
& =0.52 \mathrm{mg} \text {-sludge } /(\mathrm{mg} \text {-Tubifex } \mathrm{d}) .
\end{aligned}
$$

\subsubsection{Comparison of sludge reduction rate with direct measurement}

At the beginning of the experiment, different numbers of T. Tubifex organisms were cultivated with $35 \mathrm{ml}$ disinfected sludge. The experiment lasted for one day. At the end of the experiment, the T. Tubifex organisms were separated from the sludge. The weights of the sludge after cultivation with different numbers of $T$. Tubifex organisms are shown in Fig. 8. Seven parallel tests were conducted to calculate an average in each group. Though the average sludge weights decreased as the number of T. Tubifex organisms increased, the standard deviations were still too high. The discrete data indicated that the direct measurement' repeatability was

Table 1

The rate of $\mathrm{CO}_{2}$ increase with different numbers of Tubifex organisms ${ }^{\mathrm{a}}$

\begin{tabular}{lllllllll}
\hline Number of Tubifex & 0 & 1 & 2 & 4 & 6 & 8 & 10 \\
\hline The slope $\left(\mathrm{ppm} \mathrm{CO}_{2} / \mathrm{h}\right)$ & 27 & 48 & 110 & 269 & 552 & 835 & 1172 & 1599 \\
$P$-value & 0.923 & 0.946 & 0.970 & 0.967 & 0.993 & 0.994 & 0.995 & 0.998 \\
The level of correlation significant & 0.077 & 0.054 & 0.03 & 0.03 & 0.007 & 0.006 & 0.005 & 0.002 \\
\hline
\end{tabular}

\footnotetext{
${ }^{\text {a }}$ Results were calculated on the basis of the data before $50 \mathrm{~h}$.
} 


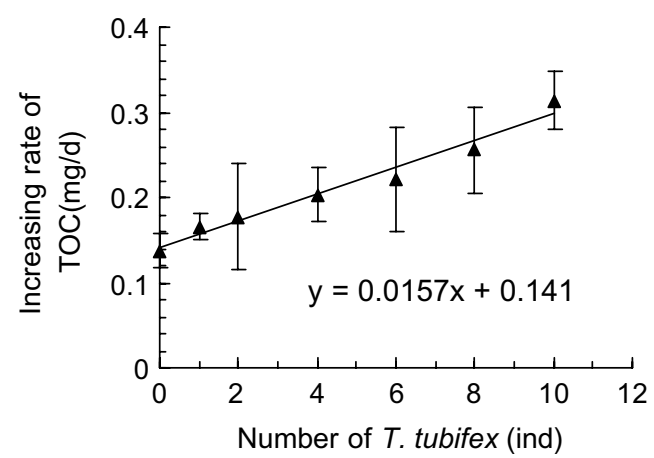

Fig. 7. The relationship between the DOC increasing rate and the number of T. tubifex organisms Increasing rates of TOC are given as mean $\pm \mathrm{SD}$ of three cores. $(P=0.983$, correlation is significant at 0.01 level, the significant 2-tailed is 0.000 .)



Fig. 8. Sludge reduction rate determined by direct measurement. Sludge dry weights are given as mean \pm SD of seven cores. $(P=-0.918$, correlation is significant at 0.01 level, the significant 2tailed is 0.01 .)

not optimal. The slope of the line was $-0.32 \mathrm{mg}$-sludge/ (ind-Tubifex $\mathrm{d}$ ), that is, the rate of sludge reduction based on the direct measurement of sludge weight was $0.64 \mathrm{mg}$-sludge/(mg-Tubifex $\mathrm{d})$. As mentioned previously, the rate of sludge reduction calculated through the transformation of the $\mathrm{C}$ element in the food chain was $0.52 \mathrm{mg}$-sludge/(mg-Tubifex $\mathrm{d})$. These results showed that the method of using $\mathrm{C}$ to measure the rate of sludge reduction was correct and accurate. Results using another microfauna, P. acuta, also confirmed this.



Fig. 9. Sludge reduction rates using different kinds of sludge. Sludge reduction rates are given as mean $\pm \mathrm{SD}$ of seven cores.

The rates of sludge reduction based on the direct measurement and this proposed method was $0.1 \mathrm{mg}$ sludge/(mg-P. acuta d) (Table 1).

\subsection{Comparison of reduction rates for different sludge samples}

Based on this new method for determining the sludge reduction rate as described previously, sludge samples from six municipal wastewater treatment plants in Beijing and Tianjin, China were tested in order to find the effect of the type of sludge on sludge reduction rate. In this comparison experiment, T. Tubifex was used as the predator. Each sludge sample was tested five times. It was found that there was no significant difference in sludge reduction rates among the different sludge samples (Fig. 9). These results indicated that T. Tubifex could consume sludge from the different plants in either city, and the rates of sludge reduction were on the same level.

\subsection{Comparison of rates for sludge reduction caused by four microfaunas' predation}

A comparison of the sludge reduction rates caused by four microfaunas' predation is shown in Table 2. $A$. hemprichi, D. magna and P. acuta, three microfaunas' $\mathrm{C}$ increasing rates during predation on sludge are shown

Table 2

Comparison of the sludge reduction rates induced by four microfaunas' predation using the proposed method and direct measurement ${ }^{\mathrm{a}}$

\begin{tabular}{lllcc}
\hline & A. hemprichi & D. magna & T. Tubifex & P. acuta \\
\hline This study & & & & \\
$R_{\mathrm{IC}}$ & $0.79 \pm 0.01$ & $0.12 \pm 0.02$ & $0.48 \pm 0.02$ & $0.06 \pm 0.01$ \\
$R_{\mathrm{OC}}$ & 0.005 & $0.06 \pm 0.02$ & $0.06 \pm 0.01$ & $0.13 \pm 0.02$ \\
$R_{\mathrm{S}}$ & $0.8 \pm 0.01$ & $0.18 \pm 0.04$ & $0.54 \pm 0.03$ & $0.18 \pm 0.03$ \\
$R_{\mathrm{S}}{ }^{\mathrm{a}}$ & n.d. & n.d. & $0.64 \pm 0.10$ & $0.07 \pm 0.05$ \\
Individual weight $(\mathrm{mg})$ & $0.0005 \pm 0.0001$ & $0.021 \pm 0.002$ & $0.5 \pm 0.02$ & $20 \pm 2$ \\
\hline
\end{tabular}

\footnotetext{
${ }^{\text {a }}$ Except for the last line, the unit is mg-C (mg-Microfauna dry weight $\left.\mathrm{d}\right)^{-1}$.
}

$\mathrm{b}$ The direct measurement was based on the sludge weights. 
in Figs. 10-12. Sludge reduction rates based on the direct measurement of sludge weight are also presented in Table 2 for T. Tubifex and P. acuta as a comparison. The sludge reduction rates based on the method proposed in this study were close to those using direct mea-

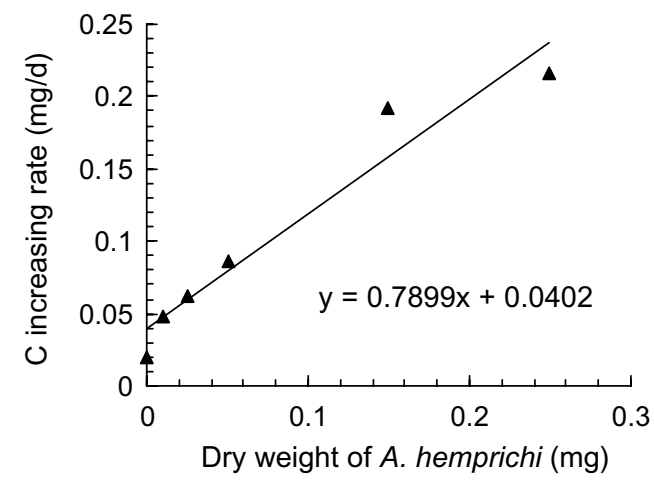

Fig. 10. Dependence of $\mathrm{CO}_{2}$ increasing rate on dry weight of $A$. hemprichi. ( $P=0.968$, correlation is significant at 0.01 level, the significant 2-tailed is 0.002 .)

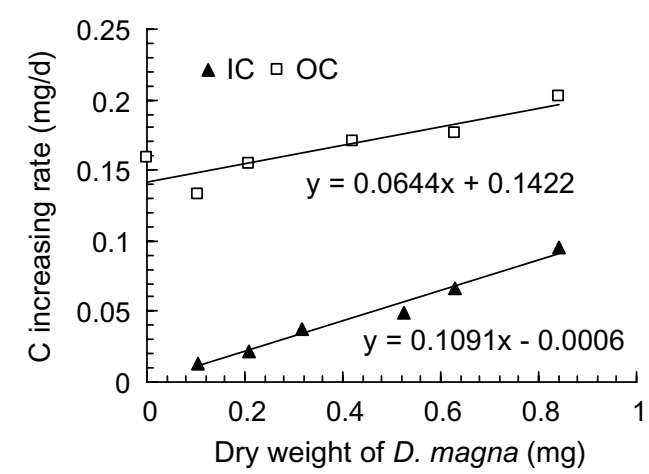

Fig. 11. Dependence of $\mathrm{C}$ increasing rate on dry weight of D. magna. ( $P$ of OC is 0.882 , correlation is significant at 0.05 level, the significant 2-tailed is $0.02 P$ of IC is 0.989 , correlation is significant at 0.01 level, the significant 2 -tailed is 0.000 .)



Fig. 12. Dependence of $\mathrm{C}$ increasing rate on dry weight of $P$. acuta. ( $P$ of $\mathrm{OC}$ is 0.930 , correlation is significant at 0.01 level, the significant 2tailed is $0.007 P$ of IC is 0.979 , correlation is significant at 0.01 level, the significant 2-tailed is 0.000 .) surement. Based on the above results, this proposed method also provides a possible way to quantify the sludge reduction rate induced by microfaunas smaller than $A$. hemprichi (such as rotifers, even ciliates), because there is no need of separating the microfauna from the sludge and easy determination of $\mathrm{CO}_{2}$ by a gas chromatography.

The results in Table 2 showed that the sludge reduction rates using various microfaunas were different for different phylum or class. The microfauna in the class of Clitellata or subclass of Oligochaeta reduced the sludge more efficiently than those in the Crustacea or the Gastropoda classes.

The sludge reduction rates of microfauna were related to their individual body size, even though they belong to the same phylum or class. For example, the sludge reduction rate of $A$. hemprichi was much higher than that of $T$. Tubifex because of their difference in individual weight. The smaller microfaunas have higher sludge reduction rates. This phenomenon may arise due to their rapid metabolism. In addition, the amount of sludge reduction caused by microfaunas is correlated to both the sludge reduction rate and the quantity of microfauna in the reactor. Though the sludge reduction rate of $A$. hemprichi was higher than that of T. Tubifex, the quantity of T. Tubifex was more than that of $A$. hemprichi in the aeration tank (results of our other experiments indicated that the quantity of T. Tubifex was 10-20 times than that of A. hemprichi). Therefore, T. Tubifex reduced more sludge than $A$. hemprichi.

\section{Conclusions}

This study was aimed to establish a method to determine the sludge reduction rates caused by four micro-faunas' predation. After thorough investigation, the following results were obtained.

The proposed indirect method has the similar accuracy with the existed direct measuring method. The rates of sludge reduction by the four microfaunas, i.e. A. hemprichi, D. magna, T. tubifex and P. acuta, were determined to be $0.8,0.18,0.54$ and $0.1 \mathrm{mg}$-sludge/ (mg-Microfauna d), respectively, which changed with the phylum or class and body size of the microfaunas. The sludge reduction rate by T. Tubifex was not significantly affected by the difference in sludge, which came from different wastewater treatment plants in different cities.

\section{Acknowledgement}

This work was supported by Science Foundation of Ministry of China (No. 20020003041). 


\section{References}

Chen, G.H., Saby, S., Djafer, M., Mo, H.K., 2001. New approaches to minimize excess sludge in activated sludge systems. Water Sci. Technol. 44 (10), 203-208.

Ellissen, H.J.H., Buys, B.R., Ratsak, C.H., 2003. In: 9th International Symposium on Aquatic Oligochaeta Application of Oligochaetes in wastewater treatment. Part B: Growth of freeswimming oligochaetes in wastewater treatment plants. 6-10 October Wageningen, The Netherlands, p. 34.

Fan, H.P., Zeng, Z.Z., Yu, P.J., Li, Z.Q., 2001. Test on Tubificidae disinfection. J. Oceanogr. Taiwan Strait 20 (4), 80-84.

Ghyoot, W., Verstraete, W., 1999. Reduced sludge production in a twostage membrane-assisted bioreactor. Water Res. 34 (1), 205-215.

Kamiya, T., Hirotsuji, J., 1998. New combined system of biological process and intermittent ozonation for advanced wastewater treatment. Water Sci. Technol. 38 (8-9), 145-153.

Low, E.U., Chase, H.A., 1999. Reducing production of excess biomass during wastewater treatment. Water Res. 33 (5), 1119-1132.

Low, E.U., Chase, H.A., Milner, M.G., Curtis, T.P., 2000. Uncoupling of metabolism to reduce biomass production in the activated sludge process. Water Res. 34 (12), 3204-3212.

Luxmy, B.S., Kubo, T., Yamamoto, K., 2001. Sludge reduction potential of metazoan in membrane bioreactors. Water Sci. Technol. 44 (10), 197-202.
Mayhew, M., Stephenson, T., 1997. Low biomass yield activated sludge: a review. Environ. Technol. 18, 883-892.

Ratsak, C.H., Maarsen, K.A., Kooijman, S.A.L.M., 1996. Effects of protozoa on carbon mineralization in activated sludge. Water Res. $30(1), 1-12$.

Rensink, J.H., Rulkens, W.H., 1997. Using metazoan to reduce sludge production. Water Sci. Technol. 36 (11), 171-179.

Rocher, M., Goma, G., Begue, A.P., Louvel, L., Rols, J.L., 1999. Towards a reduction in excess sludge production in activated sludge process: biomass physicochemical treatment and biodegradation. Appl. Microbiol. Biotechnol. 51, 883-890.

Saby, S., Djafer, M., Chen, G.H., 2002. Feasibility of using a chlorination step to reduce excess sludge in activated sludge process. Water Res. 36 (3), 656-666.

Salvado, H., Gracia, M.P., Amigo, J.M., 1995. Capability of ciliated protozoa as indicators of effluent quality in activated sludge plants. Water Res. 29 (4), 1041-1050.

Wei, Y.S., Van, H.R.T., Borger, A.R., Eikelboom, D.H., Fan, Y.B., 2003a. Comparison performances of membrane bioreactor (MBR) and conventional activated sludge (CAS) processes on sludge reduction induced by Oligochaete. Environ. Sci. Technol. 37 (14), 3171-3180

Wei, Y.S., Van, H.R.T., Borger, A.R., Eikelboom, D.H., Fan, Y.B., 2003b. Minimization of excess sludge production for biological wastewater treatment. Water Res. 37 (18), 4453-4467. 